\title{
STUDY OF A PROPERTIES OF THE OCTAGONAL MICROSTRIP ANTENNA USING METHOD OF MOMENTS (MOM)
}

\author{
EMAD SADEQ AL-JABIRI ${ }^{1,2}$ \& MAHMOUD M. AUBAIS AL-HILLO ${ }^{2}$ \\ ${ }^{1}$ General Directorate of Education in Al-Muthanna Governorate, Ministry of Education, Republic of Iraq \\ ${ }^{2}$ Department of Physics, Faculty of Science, University of Kufa, Iraq
}

\begin{abstract}
Simulation of octagonal microstrip antenna with $2.4 \mathrm{GHz}$, resonant frequency was achieved using the microwave office 2000 program (MWO2000), which is depending on the method of moments (MOM). It has been found that the proposed antenna bandwidth was 4.95\%. When the proposed antenna is modified and designed inside the circumference of a circle that its equation ${ }^{*}=a e^{\rho \theta}$.This method led to the design of another shape of the original antenna it is found that the increase in bandwidth has increased 10.13\%. The last modifying is made a rectangular slot in the patch of the antenna; it is found that the increase in bandwidth has increased to $11.61 \%$. In this study, was used Polyethylene with dielectric constant $\varepsilon_{\gamma}=2.25$, also the center of the resonant frequency was shifted to a new value.
\end{abstract}

KEYWORDS: Octagonal microstrip antenna, Bandwidth, Input impedance, Return loss \& Method of Moments

Received: Aug 16, 2020; Accepted: Sep 06, 2020; Published: Oct 30, 2020; Paper Id.: IJMPERDOCT20204

\section{INTRODUCTION}

The primary objective of any antenna's design is to transmit electromagnetic waves from a transmission line into space or to receive those waves via a receiver from space into a transmission line. The transmitting antenna is a device that converts electromagnetic waves deployed on the transmission line in order to spread free-space waves. The antenna is a part of an electrical circuit, while the other side is available at the interface with the spread of the planar wave. Hence, these antennas are devices used to transmit as well as receive radiation power. So, the antenna is considered a linking unit between transmission lines and space [1- 3]. Microstrip Patch Antenna (MPA) is commonly used because of its low profile, low cost, and ease of manufacturing. A patch antenna is made by etching metal on one side of the dielectric substrate, where on the opposite side, there is a continuous metal layer of the substrate, which forms a ground plane [4-6]. These antennas can be integrated with printed strip-line feed networks and active devices. This is a relatively new area of antenna engineering. The radiation properties of microstrip structures have been known since the mid-1950s [7].

\section{Theoretical Part}

The method of moments is one of the most accurate methods of solving electromagnetic problems, but the difficulty is to calculate the Green function [8]. If we assume that the surface current on the surface of a radiated antenna is $k$ and that the irritating area is $E^{*}$, there is the field that will be scattering $E^{s}$ so that these quantities are related to the relationship [9].

$$
e_{z} \times\left[E^{e}(x)+E^{s}(x)\right]=Z_{s}\left[e_{z} x l_{s}(x)\right] \quad(r \in S o)
$$


Where $Z_{s}$ represents the impedance and depends on the type of material made from the radiator and $\boldsymbol{E}_{\boldsymbol{I}}$ the vector unit on the vertical surface.

The scattering field is calculated from the vector magnetic voltage A (r) and the voltage $\mathrm{V}(\mathrm{r})$ where the magnetic voltage is given by the relationship [8].

$$
A(r)=\int_{g} G A\left(r \mid r^{\prime}\right) \cdot J s\left(r^{\prime}\right) d S^{r}
$$

And that the voltage is given by the relationship (3).

$$
V(r)=\int_{s} G_{V}\left(r \mid r^{r}\right) \cdot \rho_{s}\left(r^{r}\right) d S^{r}
$$

Where $\boldsymbol{G}_{A}\left(\boldsymbol{r} \mid \boldsymbol{r}^{\prime}\right), G_{\boldsymbol{V}}\left(\boldsymbol{r} \mid \boldsymbol{r}^{\prime}\right)$ The function of the diatyc Green and the function of the numerical Green respectively, and $P_{z}\left(\mathrm{r}^{\prime}\right)$ the current density. When the point of the field is very close to the source point in a material with a $\mu_{0}$ permeability and an electrical permittivity $\varepsilon=\varepsilon_{r} \varepsilon_{0}$ where $\varepsilon_{\gamma}$ is the relative permittivity, the two Green functions may be given in relation.

$$
\begin{aligned}
& G A\left(r \mid r^{\prime}\right)=\frac{\mu_{0}}{4 \pi\left|r-r_{0}\right|} \\
& G_{V}\left(r \mid r^{\prime}\right)=\frac{1}{2 \pi\left\{\varepsilon_{p}+1|| r-r_{0} \mid\right.}
\end{aligned}
$$

The purpose of solving the problem is to calculate both $l_{s}$ and $p_{s}$ Since the above integration requires knowledge of $l_{s}$ and $\rho_{s}$, numerical methods are used in the calculation of integration, where used moment of the method [8].

The solution is performed in the moment of the method, dividing the patch into rectangles $\mathrm{a} \times \mathrm{b}$ called the charged cells. Both the current and current density are defined as follows [10].

$I_{s x}=\frac{1}{b} \sum_{i=1}^{N} I_{i x} T_{x}\left(r-r_{x i}\right)$

$$
\begin{gathered}
I_{s y}=\frac{1}{a} \sum_{i=1}^{N} I_{i y} T_{y}\left(r-r_{y i}\right) \\
\rho_{s}=\frac{1}{j \omega a b}\left(\sum_{i=1}^{M} I_{i x}\left[P\left(r-r_{x i}^{+}\right)-P\left(r-r_{x i}^{-}\right)\right]+\sum_{i=1}^{N} I_{i y}\left[P\left(r-r_{y i}^{+}\right)-P\left(r-r_{y i}^{-}\right)\right]\right)
\end{gathered}
$$

Where

$$
T_{x}(r) \begin{cases}1-\frac{|z|}{a} & |x|<a,|y|<\frac{b}{2} \\ 0 & \text { elsewhere }\end{cases}
$$

$P(r)$ After making the simplifications, we get the following equation 


$$
\left(\begin{array}{ll}
c^{x x} & c^{y x} \\
c^{x y} & c^{y y}
\end{array}\right)=\frac{1}{j Z_{0}}\left(\begin{array}{l}
v_{x}^{(a)} \\
V_{y}^{(a)}
\end{array}\right)
$$

Whereas

$$
\begin{aligned}
& C_{i j}^{x x}= \\
& \frac{1}{k_{0}^{z} a b}\left[-\Gamma_{V}\left(r_{x i}^{+} \mid r_{x j}^{-}\right)-\Gamma_{V}\left(r_{x i}^{-} \mid r_{x j}^{+}\right)+\Gamma_{V}\left(r_{x i}^{+} \mid r_{x i}^{+}\right)+\Gamma_{V}\left(r_{x i}^{-} \mid r_{x j}^{-}\right)\right]-\frac{1}{k_{0} b} \int_{c_{x i}} \Gamma_{\mathrm{A}}\left(r \mid r_{x j}^{-}\right) k_{0} d x+ \\
& z_{z_{0}} \frac{z_{b}}{z_{i}} \delta_{i} \\
& c_{i j}^{x y}=\frac{1}{k_{0}^{2} a b}\left[-\mathrm{I}_{\mathrm{V}}\left(r_{x i}^{+} \mid r_{y}^{-}\right)-\mathrm{I}_{\mathrm{V}}\left(r_{x i}^{-} \mid r_{y y}^{+}\right)+\mathrm{I}_{\mathrm{V}}\left(r_{x i}^{+} \mid r_{y i}^{+}\right)+\Gamma_{\mathrm{V}}\left(r_{x i}^{-} \mid r_{y y}^{-}\right)\right]
\end{aligned}
$$

Where

$$
\begin{aligned}
& \Gamma_{V}\left(r \mid r_{0}\right)=\int \frac{\varepsilon_{0}}{k_{0}} G_{V}\left(r \mid r^{r}\right) P\left(r^{r}-r_{00}\right)\left(k_{0}^{2} d S^{\prime}\right) \\
& \mathbf{\Gamma}_{A}^{x x}\left(\mathbf{r}^{r} \mid r_{0 j}\right)=\int \frac{1}{\mu_{0} k_{0}} G_{A}^{x x}\left(r \mid r^{r}\right) T\left(r^{r}-r_{x y}\right)\left(k_{0}^{2} d S^{r}\right)
\end{aligned}
$$

And $Z_{s}$ represent the resistance of the patch and $Z_{0}=50 \Omega$ represents the impedance of the wire and $V^{\varepsilon}$ the excitation voltage is calculated according to the formula of [11] where we used the central feeder to control the amount of input impedance [12].

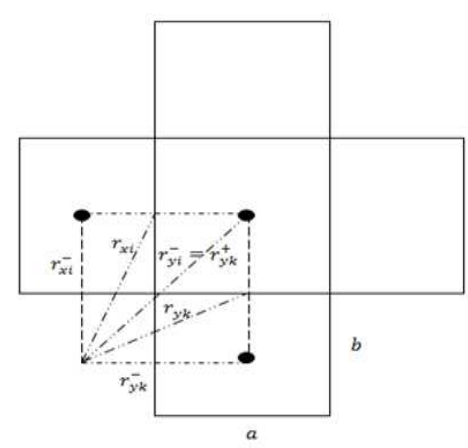

Figure 1: Shows the Values

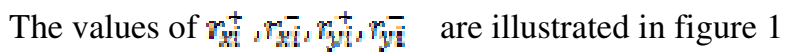

\section{3: DISCUSSION OF RESULTS}

There are several ways to expand the bandwidth, and these methods are a simple change in the patch shape. There are a lot of researchers who have developed the basic idea of this technology, and the creation of a two-slit when the radioactive edges of the patch, as these slits, do not affect the resonant frequency and radiation structures, while providing another 
resonance frequency with similar radiation characteristics that are significantly affected by the length of the incision [1315]. This is what we have done in this research and to show the amount of change that happened in the package shows as we see it.

\subsection{Octagonal Microstrip Antenna}

We initially selected an octagonal microstrip antenna which side length $(\mathrm{a}=18.2 \mathrm{~mm})$ it and the coaxial feed position at the point $\left(\gamma_{f}\right)$, as shown in figure 2 .

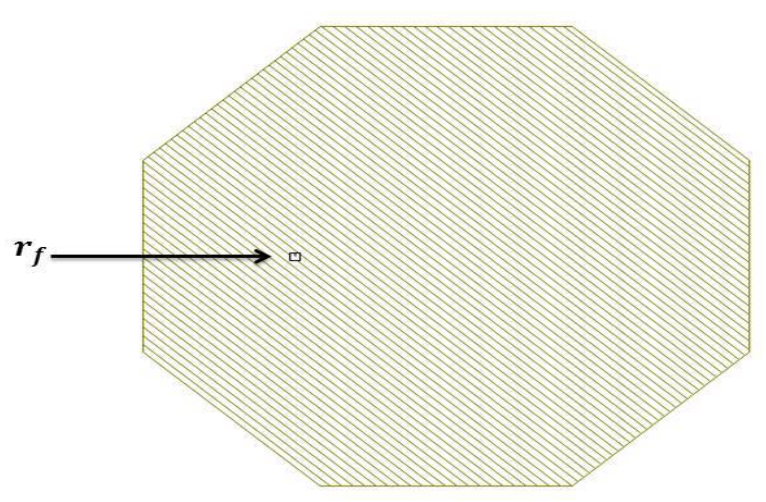

Figure 2: Octagonal Microstrip Antenna

$a=18.2 m m, h=1.59 m m \quad \varepsilon_{r}=2.25$.

The resonant frequency $\left(f_{0}\right)$ was determined by the intersecting point with the $\mathrm{X}$-axis and the return loss $s_{11}$ was calculated in Figure 3, the bandwidth is calculated from the following relationship [16]. Determined

when $\left(s_{11}=-10 d B\right)$ was the bandwidth of the proposed antenna is $(B W=4.95 \%)$

$$
B W=\frac{2\left(f_{u}-f_{l}\right)}{\left(f_{u}+f_{l}\right)} \times 100 \%
$$




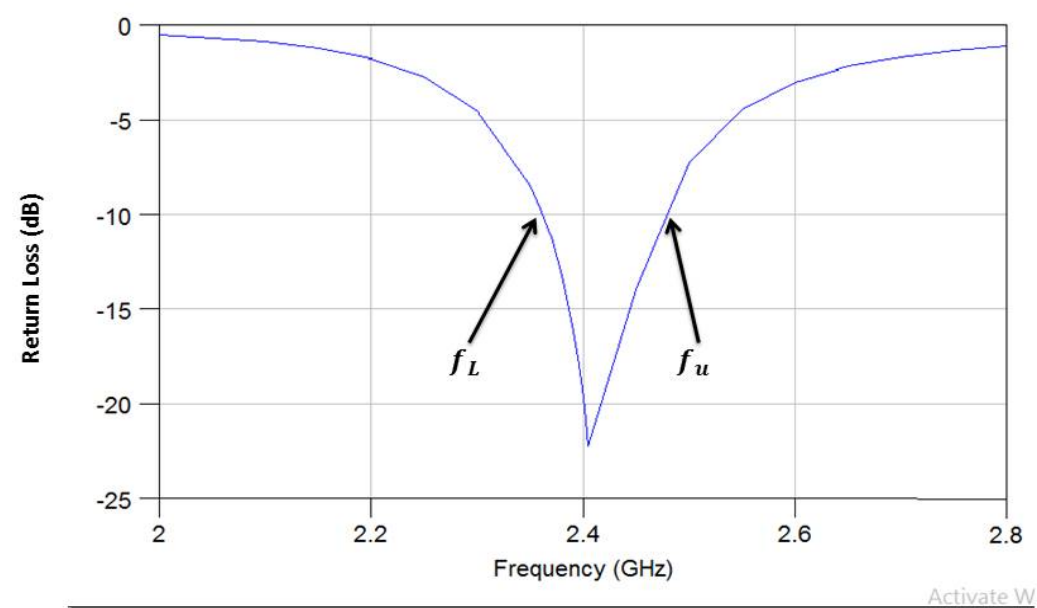

Figure 3: Return loss $s_{11}$ of the Octagonal Microstrip Antenna

$f_{l}=2.36 \mathrm{GHz}, f_{u}=2.48 \mathrm{GHz}, f_{0}=2.4 \mathrm{GHz} h=1.59 \mathrm{~mm} \varepsilon_{\mathrm{r}}=2.25$

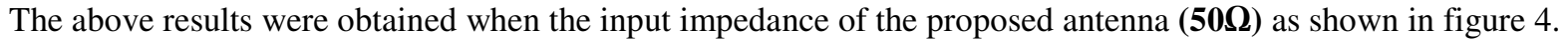

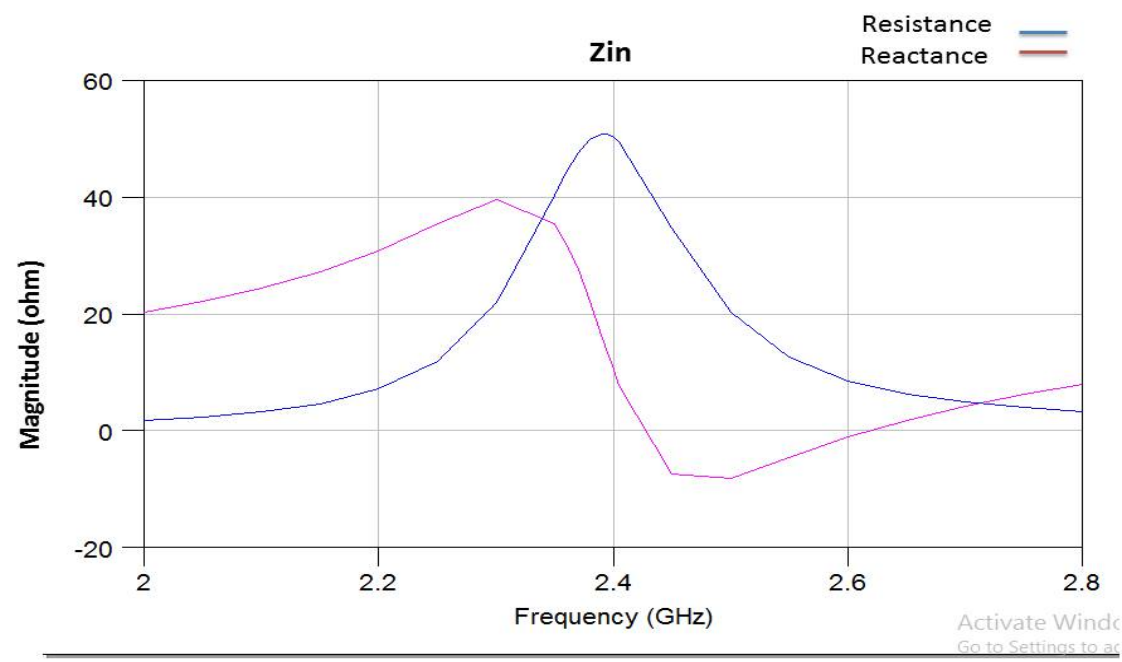

Figure 4: Input Impedance of the Octagonal Microstrip Antenna $f_{0}=2.4 \mathrm{GHz} h=1.59 \mathrm{~mm} \varepsilon_{r}=2.25$

\section{3-2 Modified Shape of Octagonal Microstrip Antenna}

The aim of this work is to enhance the bandwidth of the octagonal microstrip antenna by changing the shape of the patch; since the octagonal shape can be designed inside the circumference of a circle that its equation $r=a$, we modified the originally proposed antenna by placing the vertices of modifying octagonal inside the modified circle perimeter, its equation $r=a e^{b s}$. This method led to the design of another shape of the original antenna [17]. As show in figure 5. 


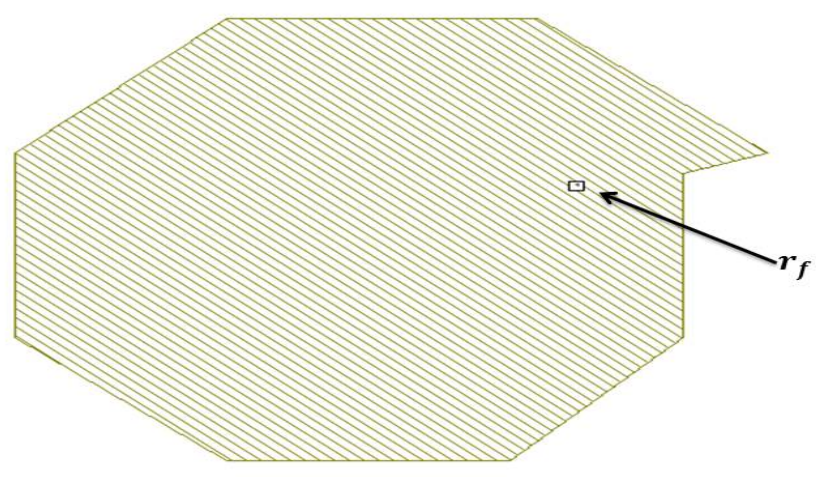

Figure 5: Modifying Octagonal Microstrip Antenna

$a=18.2 \mathrm{~mm}, h=1.59 \mathrm{~mm} \varepsilon_{r}=2.25$

After making this modification to the proposed antenna, the expansion of the amount of bandwidth has become $(10.13 \%)$. The return loss and the input impedance of the modifying octagonal microstrip antenna were shown in figure 6 , 7.

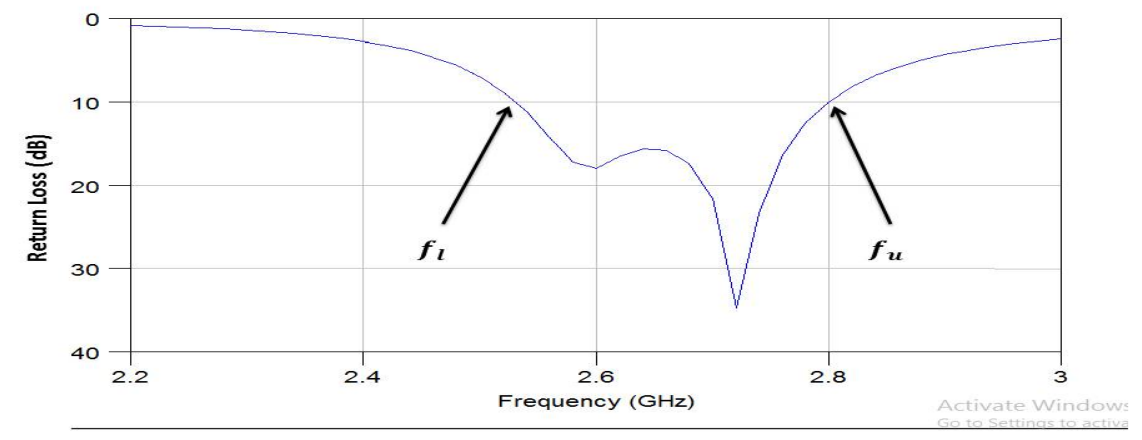

Figure 6: Return loss $s_{11}$ of the Octagonal Microstrip Antenna

$f_{l}=2.53 \mathrm{GHz}, f_{u}=2.8 \mathrm{GHz}, f_{0}=2.4 \mathrm{GHz} h=1.59 \mathrm{~mm} \varepsilon_{\gamma}=2.25$ 


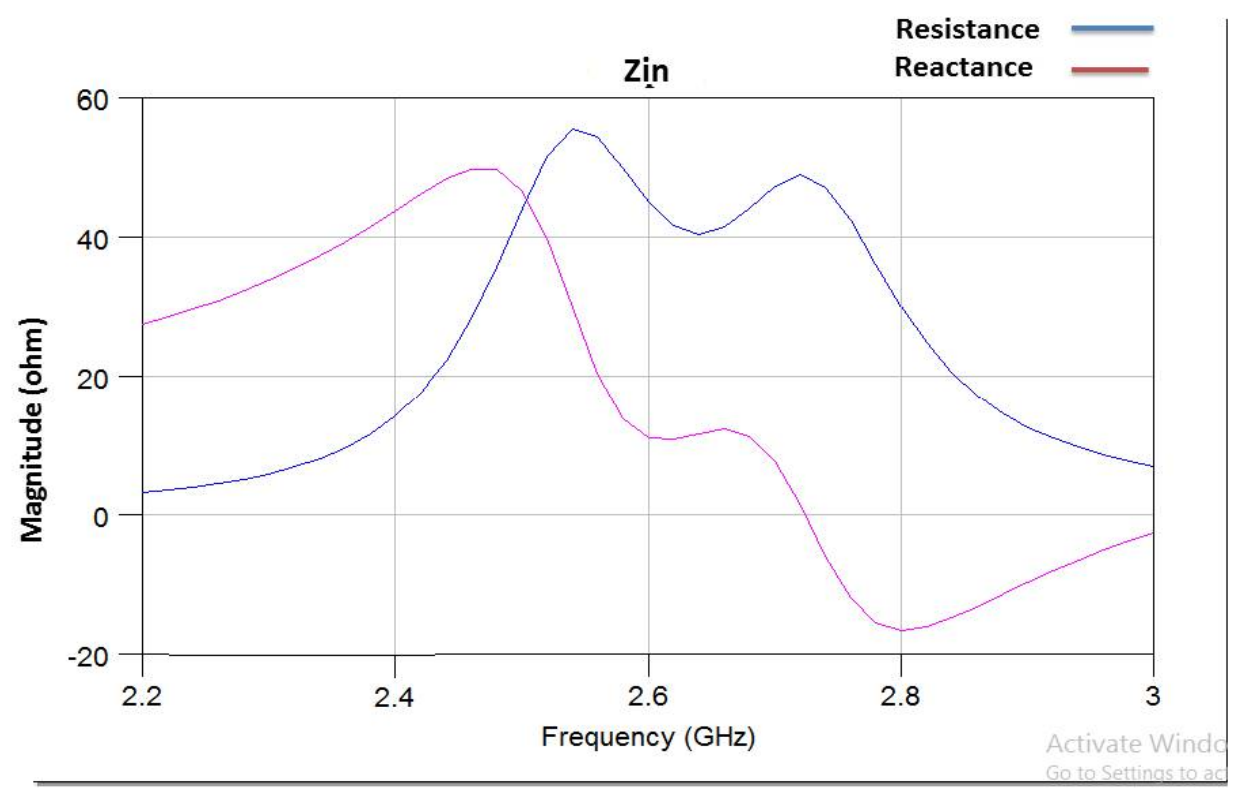

Figure 7: Input impedance of the Modifying Octagonal Microstrip Antenna

$$
f_{0}=2.4 G H z h=1.59_{m m} \varepsilon_{r}=2.25
$$

\section{3-3 Slot Octagonal Microstrip Antenna}

In order to obtain an expansion of the proposed antenna bandwidth, we made a rectangular slot on one of the ribs edges in the patch, as in figure 8 , where the dimensions of the rectangular space $(9.635,1.927)$.

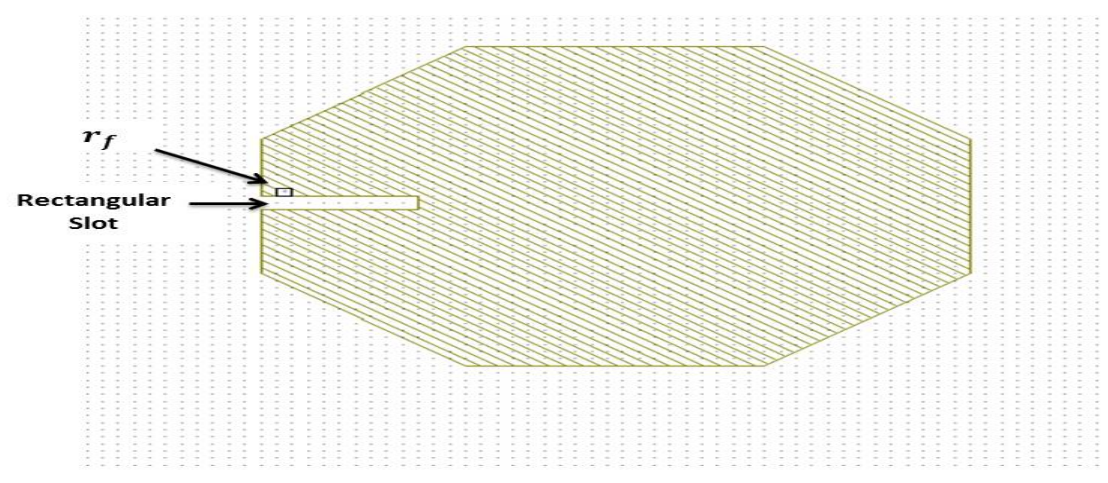

Figure 8: Slot Octagonal Microstrip Antenna $a_{1}=18.2 \mathrm{~mm}, \quad h=1.59 \mathrm{~mm} \quad \varepsilon_{r}=2.25$

After making this modification to the proposed antenna, the expansion of the amount of bandwidth has become (11.61\%). The return loss and the input impedance of the slot octagonal microstrip antenna were shown in figure $9,10$. 


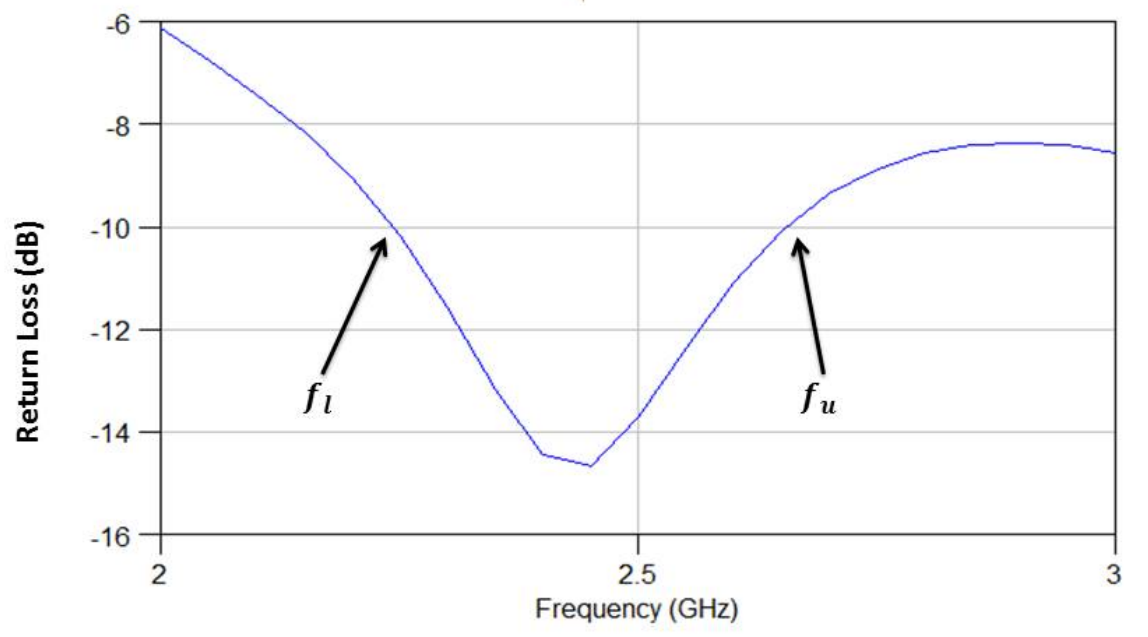

Figure 9 Return loss $s_{11}$ of the Slot Octagona Microstrip Antenna $f_{l}=2.27 \mathrm{GHz}, f_{u}=2.55 \mathrm{GHz}, f_{0}=2.4 \mathrm{GHz} h=1.59 \mathrm{~mm} \varepsilon_{r}=2.25$

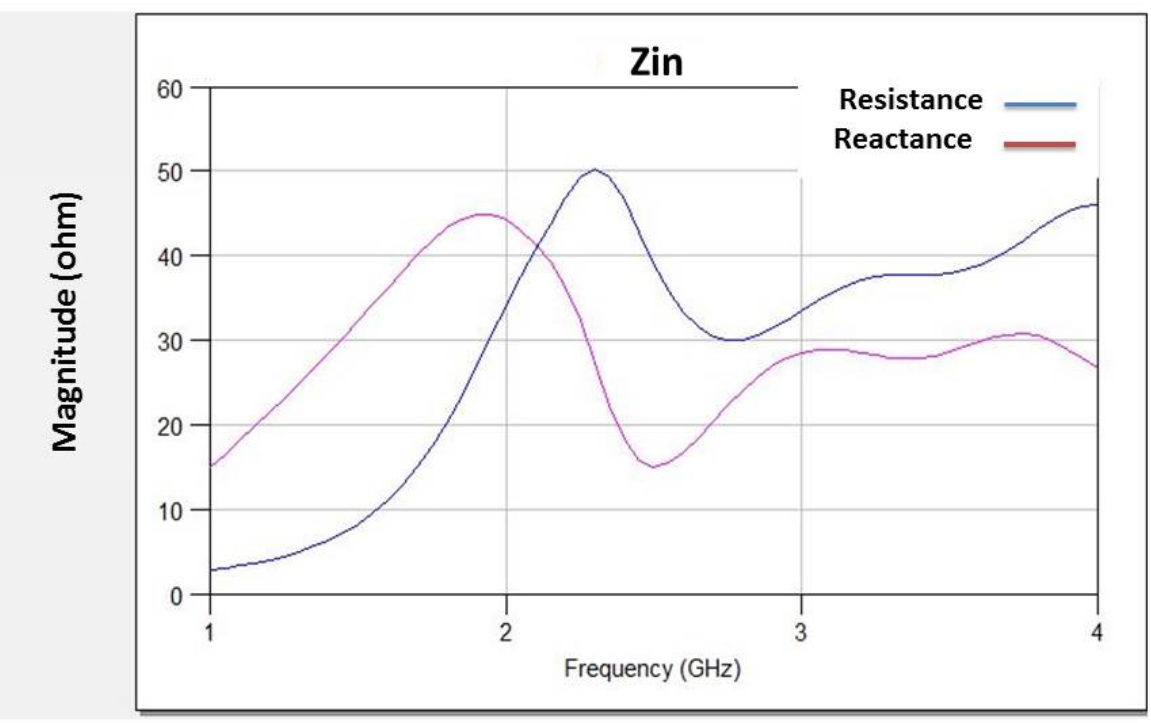

Figure 10: Input Impedance of the slot Octagonal Microstrip Antenna

$$
f_{0}=2.4 G H z \quad h=1.59 m m \quad \varepsilon_{r}=2.25
$$


To ensure that the method is generally applicable and effective, we have applied it to antennas with a different dielectric material (foam, $\boldsymbol{\varepsilon}_{r}=\mathbf{1 . 0 7}$ ) with the center of the resonant frequency was shifted to a new high value $\left(f_{0}=3.5 \mathrm{GHz}\right)$, As shown in the following table.

Table 1: The Bandwidth and Resonant Frequency for Proposed Antenna

\begin{tabular}{|c|c|c|c|c|}
\hline \multirow{2}{*}{$\begin{array}{c}\text { Dielectric } \\
\text { constant value }\end{array}$} & Resonant frequency & $\begin{array}{c}\text { Octagonal } \\
\text { microstrip }\end{array}$ & $\begin{array}{c}\text { Modified } \\
\text { Octagonal }\end{array}$ & Slot Octagonal \\
\cline { 2 - 5 } & Bandwidth & Bandwidth & Bandwidth \\
\hline 2.25 & $2.4 \mathrm{GHz}$ & $4.95 \%$ & $10.13 \%$ & $11.61 \%$ \\
\hline 1.07 & $3.5 \mathrm{GHz}$ & $8.11 \%$ & $12.07 \%$ & $13.25 \%$ \\
\hline
\end{tabular}

\section{CONCLUSIONS}

When designing an octagonal microstrip antenna, its bandwidth (4.95\%) was calculated at a resonant frequency (2.4 GHz) and input impedance $50 \Omega$. In order to increase the bandwidth of the proposed antenna, the following was done:

- Modifying of octagonal microstrip antenna and designed inside circumference of a circle that its equation $\gamma=a \theta^{b s}$.This method led to the design of another shape of the original antenna it is found that the increase in bandwidth has increased by $10.13 \%$.

- A rectangular slot was made on one of the ribs edges in the patch for the proposed antenna. This modification increased the bandwidth to $(11.61 \%)$.

- When the proposed antenna was applied to another resonant frequency and different dielectric, there was a significant increase in bandwidth, where the bandwidth values in the proposed antenna are increased the lower the dielectric constant of the insulating material.

\section{ACKNOWLEDGMENT}

The authors would like to thank the Department of Physics, Faculty of Science at the University of Kufa, for the material and moral assistance that has been made in the success of this research.

\section{REFERENCES}

1. G. J. Foschini, "Layered space-time architecture for wireless communication in a fading environment when using multielement antennas,” Bell Labs Tech. J., 1996, doi: 10.1002/bltj.2015.

2. J. A. Yabagi, M. I. Kimpa, B. L. Muhammad, M. Q. Hamzah, H. K. A. Kadir, and M. Arif Agam, "The Effect of Silver Particles on the Synthesis and Characterization of Polystyrene/Silver (Ps/Ag) Nanocomposites for Carbonaceous Materials," Int. J. Nanoelectron. Mater., vol. 13, no. 2, pp. 263-282, 2020.

3. M. A. Agam, M. Q. Hamzah, B. D. Juilis, S. Ashikin, and J. A. Yabagi, "POLYSTYRENE EMBEDDED SILVER NANOPARTICLES AS POTENTIAL ZINC HEAVY METALS REMOVAL IN WASTEWATER REMEDIATION APPLICATION,” Int. J. Mech. Prod. Eng. Res. Dev., vol. 10, no. 3, pp. 213-220, 2020.

4. A. Arora, A. Khemchandani, Y. Rawat, S. Singhai, and G. Chaitanya, "Comparative study of different feeding techniques for rectangular microstrip patch antenna," Int. J. Innov. Res. Electr. Electron. Instrum. Control Eng., 2015, doi: 10.17148/IJIREEICE.2015.3509. 
5. M. Q. Hamzah, S. O. Mezan, A. N. Tuama, A. H. Jabbar, and M. A. Agam, "Study and Characterization of Polystyrene/Titanium Dioxide Nanocomposites (PS/TiO2 NCs) for Photocatalytic Degradation Application : a Review, ” Int. J. Eng. Technol., vol. 7, pp. 538-543, 2018.

6. M. A. Agam, N. N. Awal, S. A. Hassan, J. A. Yabagi, M. Q. Hamzah, and A. Talib, "Energy Band Gap Investigation of Polystyrene Copper Oxide Nanocomposites Bombarded with Laser,” J. Adv. Res. Fluid Mech. Therm. Sci., vol. 66, no. 2, pp. 125-135, 2020.

7. C. Ingale, T. Ingale, and A. Trikolikar, "Study of Different Types of Microwave Antenna and Its Applications," ISSN Int. J. Comput. Technol. Electron. Eng. An ISO Certif. Journal. E-NSPIRE, 2013.

8. R. A. Kipp and C. H. Chan, "A Numerically Efficient Technique for the Method of Moments Solution for Planar Periodic Structures in Layered Media," IEEE Trans. Microw. Theory Tech., 1994, doi: 10.1109/22.285070.

9. B. Borden, "Mathematical problems in radar inverse scattering," Inverse Problems. 2002, doi: 10.1088/0266-5611/18/1/201.

10. T. Srivastava et al., "Large-Voltage Tuning of Dzyaloshinskii-Moriya Interactions: A Route toward Dynamic Control of Skyrmion Chirality," Nano Lett., 2018, doi: 10.1021/acs.nanolett.8b01502.

11. J. B. Patton and D. Curtice, "Analysis of utility protection problems associated with small wind turbine interconnections," IEEE Trans. Power Appar. Syst., 1982, doi: 10.1109/TPAS.1982.317073.

12. M. Svanda and M. Polivka, "Matching Technique for an On-Body Low-Profile Coupled-Patches UHF RFID Tag and for Sensor Antennas,” IEEE Trans. Antennas Propag., 2015, doi: 10.1109/TAP.2015.2403399.

13. P. Y. Qin, A. R. Weily, Y. J. Guo, and C. H. Liang, "Polarization reconfigurable U-slot patch antenna," IEEE Trans. Antennas Propag., 2010, doi: 10.1109/TAP.2010.2055808.

14. M. Q. Hamzah, M. S. bin Roslan, H. M. Zaid, and M. A. Agam, "Effect study of H2O2 and THF on the preparation and characterization of polystyrene/ TiO2 nanomaterials, "Solid State Technol., vol. 63, no. 6, pp. 3347-3358, 2020.

15. M. A. Agam and Q. Guo, Electron beam modification of polymer nanospheres. J Nanosci Nanotechnol. 2007 Oct;7(10):36159. doi: 10.1166/jnn.2007.814. PMID: 18330181.

16. B. Henin and A. Abbosh, "Design of compact planar crossover using Sierpinski carpet microstrip patch," IET Microwaves, Antennas Propag., 2013, doi: 10.1049/iet-map.2012.0262.

17. BC. Y. Gan, K. S. M. Sahari, and C. S. Tan, "Numerical investigation on Coanda flow over a logarithmic surface," J. Mech. Sci. Technol., 2015, doi: 10.1007/s12206-015-0615-y. 